\title{
BMJ
}

\section{Slow walking speed and cardiovascular death in well functioning older adults: prospective cohort study}

\author{
Julien Dumurgier, neurologist, ${ }^{1,2,3}$ Alexis Elbaz, epidemiologist, ${ }^{1,2}$ Pierre Ducimetière, senior epidemiologist, ${ }^{4,5}$ \\ Béatrice Tavernier, geriatrician, ${ }^{6}$ Annick Alpérovitch, senior epidemiologist, ${ }^{1,2}$ Christophe Tzourio, head of the \\ Inserm neuroepidemiology unit,
}

\section{1'INSERM, U708, F-75013, Paris, \\ France \\ ${ }^{2}$ UPMC Univ Paris 06, F-75005, Paris, France \\ ${ }^{3}$ CMRR Paris Nord-IDF, GH Lariboisière - Fernand Widal, F-75010, Paris, France \\ ${ }^{4}$ INSERM, U780, Villejuif, France \\ ${ }^{5}$ Université Paris-Sud, France \\ ${ }^{6} \mathrm{CHU}$ de Dijon, Department of Geriatrics, F-21000, Dijon, France Correspondence to: Alexis Elbaz alexis.elbaz@upmc.fr \\ Cite this as: $B M J$ 2009;339:b4460 doi:10.1136/bmj.b4460}

\section{ABSTRACT}

Objective To study the relation between low walking speed and the risk of death in older people, both overall and with regard to the main causes of death.

Design Prospective cohort study.

Setting Dijon centre (France) of the Three-City study. Participants 3208 men and women aged $\geq 65$ living in the community, recruited from 1999 to 2001 , and followed for an average of 5.1 years.

Main outcome measures Mortality, overall and according to the main causes of death, by thirds of baseline walking speed (measured at maximum speed over six metres), adjusted for several potential confounders; Kaplan-Meier survival curves by thirds of baseline walking speed. Vital status during follow-up. Causes of death.

Results During 16414 person years of follow-up, 209 participants died (99 from cancer, 59 from cardiovascular disease, 51 from other causes). Participants in the lowest third of baseline walking speed had an increased risk of death (hazard ratio 1.44, 95\% confidence interval 1.03 to 1.99) compared with the upper thirds. Analyses for specific causes of death showed that participants with low walking speed had about a threefold increased risk of cardiovascular death $(2.92,1.46$ to 5.84$)$ compared with participants who walked faster. There was no relation with cancer mortality $(1.03,0.65$ to 1.70$)$. In stratified analyses, cardiovascular mortality was increased across various strata defined by sex, median age, median body mass index (BMI), and level of physical activity.

Conclusion Slow walking speed in older people is strongly associated with an increased risk of cardiovascular mortality.

\section{INTRODUCTION}

There is growing interest in using walking speed in ambulatory clinics to readily assess functional status and motor performances in older people, and walking speed has been recommended as a possible "vital sign." ${ }^{\prime \prime}$ A few studies in well functioning older people have shown that decreased walking speed can predict adverse health related events such as falls, ${ }^{23}$ disability, ${ }^{4}$ admissions to hospital, ${ }^{56}$ and "persistent lower extremity limitation."7 Lower walking speed has also been associated with increased all cause mortality, ${ }^{8}$ but it is unknown whether specific causes of death account for this increased mortality.

As part of a prospective cohort of well functioning older people enrolled in the Three-City (3C) study we studied the prognostic value of walking speed by investigating its relation with mortality overall and according to main causes of death. Because of recent evidence indicating that vascular risk factors might be associated with decreased motor performances,${ }^{910}$ we had a special interest in the relation between walking speed and risk of cardiovascular death.

\section{METHODS}

The $3 \mathrm{C}$ study is an ongoing cohort study conducted in three French cities (Bordeaux, Dijon, Montpellier). Details of the study and primary outcomes have been previously reported. ${ }^{11}$ Participants aged $\geq 65$ and living in the community were recruited from electoral rolls. The first step of the sampling procedure was to select administrative districts. Eligible inhabitants of the selected districts were invited to participate by a letter and were then contacted by phone until we reached our target number of participants; the acceptance rate was 37\%. Data for the present study were obtained in Dijon ( $\mathrm{n}=4931$ ), where investigators were interested in motor function in older people. After baseline examination, follow-up examinations were performed at a mean of 1.8 years (2001-2), 3.6 years (2003-4), and 5 . 1 years (2005-6).

\section{Baseline assessments}

During a face-to-face interview in participants' homes in 1999-2001 trained psychologists collected baseline demographic and medical data using standardised questionnaires. Education was defined as a four level variable (no school/primary without diploma, primary with diploma, secondary without a baccalaureate degree, baccalaureate/university degree). Participants were asked about their history of coronary artery disease (myocardial infarction, angina pectoris, coronary revascularisation), peripheral artery disease, stroke, Parkinson's disease, and recent hip fracture (in the two preceding years). Exertional dyspnoea was self declared, based on the New York Heart Association 
(NYHA) classification. Blood pressure was measured twice during the baseline interview, and the average of these two measurements was used. Hypertension was defined as high blood pressure (systolic blood pressure $\geq 140 \mathrm{~mm} \mathrm{Hg}$ or diastolic blood pressure $\geq 90 \mathrm{~mm} \mathrm{Hg}$ ) or use of antihypertensive medication. Participants were considered to have diabetes if they used antidiabetic agents or if their fasting glucose concentration was $\geq 7.0 \mathrm{mmol} / \mathrm{l}$. Hypercholesterolaemia was defined as total cholesterol $\geq 6.2 \mathrm{mmol} / \mathrm{l}$ or use of lipid lowering drugs. Smoking status was classified as current, past, or never. Weight and height were measured and used to calculate body mass index (BMI). Chronic use of nonsteroidal anti-inflammatory drugs (NSAIDs) for joint pain was assessed and considered as a surrogate for rheumatic disease. Baseline physical activity was self reported as a three level variable assessing the daily duration of walking and athletic activities.

Depressive symptoms were assessed with the Center for Epidemiologic Studies Depression Scale (CESD)..$^{12}$ Use of psychotropic drugs (anxiolytics, hypnotics, antidepressants) was also assessed. Participants underwent a battery of cognitive tests, including the mini-mental state examination (MMSE). The ability to complete instrumental activities of daily living (Lawton IADL scale) was assessed. Diagnosis of dementia was established with a three phase procedure: participants were screened using the mini-mental state examination and the Isaac set test; a neurologist then examined those with positive results. The final diagnosis was established by a panel of independent neurologists using criteria from the Diagnostic and Statistical Manual of Mental Disorders, fourth edition. ${ }^{11}$

Fasting blood samples were taken and glycaemia, total cholesterol, and homocysteine concentrations were measured at a single laboratory.

\section{Gait assessment}

After the baseline home interview, participants aged $\leq 85$ were invited to the study centre in 1999-2001, where we quantitatively evaluated walking speed. Two photoelectric cells connected to a chronometer were placed in a corridor six metres apart. Participants were first asked to walk at their usual speed and were then invited to perform the maximum walking speed test. They were asked to walk down the corridor as fast as possible without running ("Please walk as quickly as you can without running to the end of the corridor"). They could do one trial to check whether they understood the instructions before we measured the actual speed. In addition, participants started walking three metres before the start line so that walking speed did not include the acceleration time. Walking speed was defined as the ratio between distance and time.

\section{Outcomes}

At each follow-up, we contacted participants; when we could not reach them we contacted their relatives and personal physicians to determine their vital status. In case of death we obtained hospital records and information from personal physicians. A committee reviewed records to determine immediate and underlying causes of death, according to ICD-10 (international classification of diseases, 10th revision) codes. The committee was blinded to the results of walking speed measured once in 1999-2001.

We first considered all cause death and then defined three subgroups: cancer, cardiovascular, other causes. Cancer mortality was defined as an immediate cause of death coded by the committee between $\mathrm{C} 00$ and $\mathrm{C} 97$ and cardiovascular death as an immediate cause of death coded between I00 and I78 (including coronary heart disease, stroke, peripheral vascular disease, and other cardiovascular disease) or R960 (sudden death). Other causes of deaths included infectious diseases, digestive causes, trauma, suicide, and death of undetermined cause.

\section{Statistical analyses}

We excluded from our analyses participants who had conditions at baseline that were strongly associated with decreased walking speed (Parkinson's disease, dementia, hip fracture in the previous two years, disabling stroke, coronary artery disease). Descriptive statistics were used to describe baseline characteristics by vital status (deceased during follow-up, yes/no) and thirds of walking speed. We compared groups using Student's $t$ test or analysis of variance (with linear contrasts) for continuous measures and $\chi^{2}$ test or CochranArmitage trend test for proportions. Because walking speed was strongly related to sex, we categorised it into sex dependent thirds to maintain balanced sample sizes in men and women (cut offs were defined by tertiles of the distributions in men and women: $\leq 1.50 \mathrm{~m} / \mathrm{s}$, $1.51-1.84 \mathrm{~m} / \mathrm{s}$, and $\geq 1.85 \mathrm{~m} / \mathrm{s}$ in $\mathrm{men} ; \leq 1.35 \mathrm{~m} / \mathrm{s}, 1.36$ $1.50 \mathrm{~m} / \mathrm{s}$, and $>1.50 \mathrm{~m} / \mathrm{s}$ women).

We calculated the cumulative incidence of death according to thirds of walking speed with the KaplanMeier method and compared it with the log rank test. We also computed the cumulative risk of a given cause of death taking into account other causes of death (competing risk analysis) and found similar estimates to the Kaplan-Meier ones because mortality rates were low, thus showing that competing risks are not an issue for the present analyses. We used Cox proportional hazard models to estimate hazard ratios for death and their 95\% confidence intervals. The proportional hazards assumption was checked by computing Schoenfeld residuals. We tested interactions between variables by including interaction terms. Unadjusted and adjusted hazard ratios are presented. Models were initially adjusted for age and sex. We then included in the models additional covariates strongly associated with walking speed (education level, minimental state examination, BMI, height, baseline physical activity). In the full model, we adjusted for other covariates associated with walking speed or mortality in univariate analyses (diabetes mellitus, hypertension, use of non-steroidal anti-inflammatory drugs for joint pain, use of psychotropic drugs, alcohol drinking, cigarette smoking, homocysteine concentration, dyslipidaemia, exertional dyspnoea, peripheral artery 
disease, instrumental activities of daily living, depressive symptoms). In sensitivity analyses, we considered walking speed as a continuous variable or used other cut points (quartiles, quintiles) to categorise walking speed to assess whether our findings were influenced by the coding of the walking speed variable. Stratified analyses were performed to assess the relation between walking speed and cardiovascular mortality in different subgroups defined by sex, median age, median BMI, hypertension, smoking, and physical activity level. In sensitivity analyses, participants who reported coronary artery disease at baseline were retained in the analyses.

All $\mathrm{P}$ values were two tailed, and $\mathrm{P} \leq 0.05$ was considered to be significant. All statistical analyses were performed with SAS version 9.1 (SAS Institute, Cary, NC, USA).

\section{RESULTS}

At baseline, 4399 participants aged 65-85 were seen at the study centre. We excluded from the analyses 722 who had one or more prevalent medical conditions strongly associated with decreased walking speed (477 with coronary artery disease, 211 with stroke, 53 with Parkinson's disease, 38 with dementia, 12 with hip fracture). Walking speed at baseline was missing for 469 participants, who tended to be older $(\mathrm{P}<0.001)$ and with a higher $\mathrm{BMI}(\mathrm{P}<0.001)$ than the other participants; there was no difference for other characteristics. All cause mortality during follow-up was not significantly higher $(\mathrm{P}=0.12)$ in participants without a measure of walking speed compared with those with a measure available. The mean (SD) age of the 3208 participants included in the study was 73.2 (4.6); 2085 $(65 \%)$ were women. Vital status was determined for $3200(99.8 \%)$ and missing for $8(0.2 \%)$ at the end of the third follow-up (2005-6). During a mean (SD) follow-up of 5.1 (1.0) years, corresponding to 16414 person years, 209 participants died (99 from cancer, 59 from cardiovascular disease, 51 from other causes).

Table 1 summarises participants' baseline characteristics by vital status and thirds of walking speed. Those who died during follow-up were older, taller, more often men, and had a higher prevalence of cardiovascular risk factors (diabetes mellitus, hypertension, smoking) compared with survivors. About half of those who died were in the lowest third of walking speed, compared with one third of those who remained alive. Those in the lowest third of walking speed were older, smaller, had higher BMI, and were more likely to have depressive symptoms, less education, lower mini-mental state examination scores, and lower physical activity levels than those in the upper thirds of walking speed. They were also more likely to have hypertension or diabetes, have exertional dyspnoea or peripheral artery disease, and die during follow-up (table 1). There were no significant differences in baseline characteristics according to causes of mortality (data not shown), except for chronic use of non-steroidal anti-inflammatory drugs, which was associated with an increased cardiovascular mortality $(\mathrm{P}=0.03)$.

Figure 1 shows the cumulative risk of death (all cause, cancer, cardiovascular, other causes) by thirds of walking speed. There was a significant difference in all cause mortality across thirds of walking speed (log rank, $\mathrm{P}<0.001)$. Kaplan-Meier curves began to separate between 20 and 30 months after baseline and continued to diverge afterwards. The difference in the cumulative risk of death was significant for
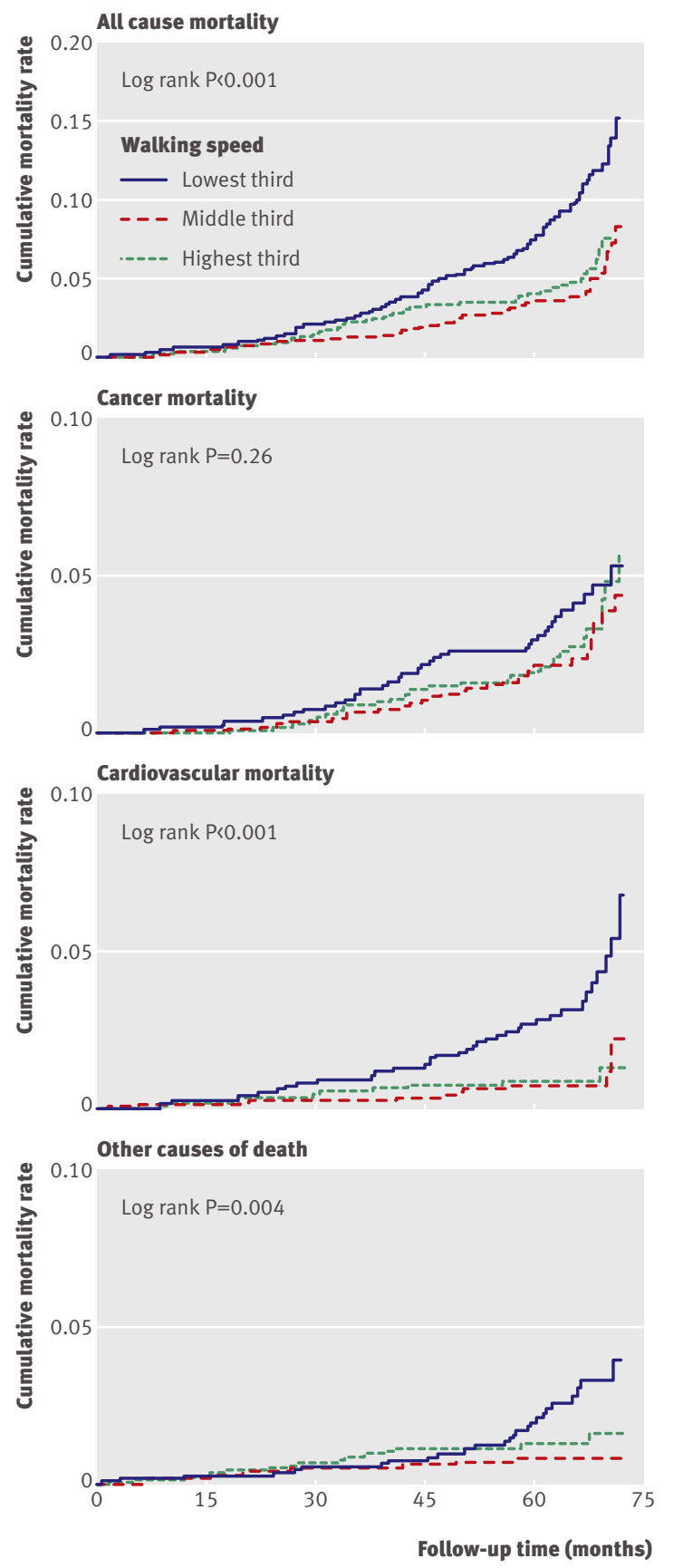

Fig 1 | Kaplan-Meier estimates of cumulative incidence of death according to thirds of walking speed, overall and by cause of death. Cut offs (tertiles) for definition of thirds of walking speed were $\leq 1.50 \mathrm{~m} / \mathrm{s}, 1.51-1.84 \mathrm{~m} / \mathrm{s}$, and $\geq 1.85 \mathrm{~m} / \mathrm{s}$ for men and $\leq 1.35 \mathrm{~m} / \mathrm{s}, 1.36-1.50 \mathrm{~m} / \mathrm{s}$, and $>1.50 \mathrm{~m} / \mathrm{s}$ for women 
Table 1|Baseline characteristics of study sample by vital status and thirds of walking speed. Figures are numbers (percentages) unless stated otherwise

\begin{tabular}{|c|c|c|c|c|c|c|c|c|c|}
\hline \multirow[b]{2}{*}{ Characteristics } & \multirow[b]{2}{*}{$\begin{array}{c}\text { Overall } \\
(n=3208)\end{array}$} & \multirow[b]{2}{*}{ Missing } & \multicolumn{3}{|c|}{ Died during follow-up* } & \multicolumn{4}{|c|}{ Thirds of walking speed $\dagger$} \\
\hline & & & $\begin{array}{c}\text { No } \\
(n=2991)\end{array}$ & $\begin{array}{c}\text { Yes } \\
(n=209)\end{array}$ & P value $\neq$ & $\begin{array}{l}\text { Lowest } \\
(n=1091)\end{array}$ & $\begin{array}{c}\text { Middle } \\
(n=1087)\end{array}$ & $\begin{array}{l}\text { Highest } \\
(n=1030)\end{array}$ & Pvalue \\
\hline Mean (SD) age (years) & $73.2(4.6)$ & 0 & $73.1(4.5)$ & $75.5(4.6)$ & $<0.001$ & $74.9(4.6)$ & $73.1(4.4)$ & $71.6(4.2)$ & $<0.001$ \\
\hline Women & $2070(64.5)$ & 0 & $1968(65.8)$ & $98(46.9)$ & $<0.001$ & $717(65.7)$ & $691(63.6)$ & $662(64.3)$ & 0.48 \\
\hline Mean (SD) BMI & $25.6(4.0)$ & 2 & $25.6(4.0)$ & $25.9(4.6)$ & 0.22 & $26.6(4.4)$ & $25.4(3.8)$ & $24.8(3.5)$ & $<0.001$ \\
\hline Mean (SD) height (cm) & $161.5(8.64)$ & 2 & $161.4(8.6)$ & $162.9(8.9)$ & 0.01 & $160.0(8.5)$ & $161.6(8.8)$ & $162.9(8.4)$ & $<0.001$ \\
\hline Low education levelף & $651(20.3)$ & 1 & $602(20.1)$ & $48(23.0)$ & 0.80 & $282(25.8)$ & $208(19.1)$ & $161(15.6)$ & $<0.001$ \\
\hline Mean (SD) MMSE score & 27.5 (1.9) & 4 & $27.5(1.9)$ & $27.1(2)$ & 0.01 & $27.0(2.1)$ & $27.6(1.8)$ & $27.8(1.7)$ & $<0.001$ \\
\hline Depressive symptoms ${ }^{\star \star}$ & $390(12.2)$ & 29 & $361(12.1)$ & $26(12.5)$ & 0.89 & $183(17.0)$ & $112(10.4)$ & $95(9.3)$ & $<0.001$ \\
\hline Psychotropic drugs use & $785(24.5)$ & 0 & $723(24.2)$ & $60(28.7)$ & 0.14 & $352(32.3)$ & $241(22.2)$ & $192(18.6)$ & $<0.001$ \\
\hline IADL dependent†† & $171(5.3)$ & 23 & $149(5.0)$ & $20(9.7)$ & 0.004 & $97(9.0)$ & $49(4.5)$ & $25(2.4)$ & $<0.001$ \\
\hline Low physical activitył‡ & $517(16.4)$ & 46 & $476(16.5)$ & $41(21.1)$ & 0.09 & $228(22.1)$ & $156(14.7)$ & $133(13.3)$ & $<0.001$ \\
\hline Hypertension§§ & $2513(78.3)$ & 0 & $2326(77.8)$ & $182(87.1)$ & 0.002 & $925(84.8)$ & $845(77.7)$ & $743(72.1)$ & $<0.001$ \\
\hline Diabetes mellitus & $262(8.2)$ & 0 & $224(7.5)$ & $38(18.2)$ & $<0.001$ & $113(10.4)$ & $82(7.5)$ & $67(6.5)$ & 0.001 \\
\hline Hypercholesterolaemia|โा & $1856(57.9)$ & 1 & $1741(58.2)$ & $112(53.9)$ & 0.22 & $633(58.1)$ & $623(57.3)$ & $600(58.3)$ & 0.90 \\
\hline Mean (SD) homocysteine $(\mu \mathrm{mol} / \mathrm{l})$ & $14.7(5.2)$ & 103 & $14.6(5.2)$ & $15.0(4.89)$ & 0.30 & $15.4(5.7)$ & $14.6(5.1)$ & $14.0(4.5)$ & $<0.001$ \\
\hline Former or current smokers & $1175(36.6)$ & 0 & $1072(35.8)$ & $99(47.4)$ & 0.01 & 381 (34.9) & $396(36.4)$ & $398(38.6)$ & 0.48 \\
\hline Current drinker & $2532(78.9)$ & 8 & $2362(79.2)$ & $164(78.5)$ & 0.81 & $855(78.4)$ & $849(78.2)$ & $828(80.7)$ & 0.24 \\
\hline Peripheral artery disease & $76(2.4)$ & 43 & $61(2.0)$ & $14(6.7)$ & $<0.001$ & $40(3.7)$ & $17(1.6)$ & $19(1.9)$ & 0.005 \\
\hline Exertional dyspnoea & 381 (11.9) & 7 & $334(11.2)$ & $45(21.6)$ & $<0.001$ & $199(18.3)$ & $109(10.0)$ & $73(7.1)$ & $<0.001$ \\
\hline NSAIDs for joint pain & $474(14.8)$ & 37 & $443(15.0)$ & $30(14.6)$ & 0.87 & $216(20.1)$ & $152(14.2)$ & $106(10.4)$ & $<0.001$ \\
\hline Walking speed in lower third & $1091(34.0)$ & 0 & $982(32.8)$ & $105(50.2)$ & $<0.001$ & - & - & - & 一 \\
\hline Died during follow-up & $209(6.5)$ & 8 & - & - & - & $105(9.7)$ & $49(4.5)$ & $55(5.4)$ & $<0.001$ \\
\hline
\end{tabular}

$\mathrm{BMI}=$ body mass index; MMSE=mini-mental state examination, IADL=instrumental activity of daily living; NSAID=non-steroidal anti-inflammatory drug.

*Vital status not determined for eight people.

†Cut offs (tertiles): $\leq 1.50 \mathrm{~m} / \mathrm{s}, 1.50-1.85 \mathrm{~m} / \mathrm{s}$, and $\geq 1.85 \mathrm{~m} / \mathrm{s}$ for men and $\leq 1.35 \mathrm{~m} / \mathrm{s}, 1.35-1.50 \mathrm{~m} / \mathrm{s}$, and $>1.50 \mathrm{~m} / \mathrm{s}$ for women.

$\mp \mathrm{X}^{2}$ test for proportions and Student's $t$ test for continuous measures.

$\S$ Cochran-Armitage trend test for proportions and analysis of variance (linear contrasts) for continuous measures.

\No school or primary school without diploma.

**Assessed by Center of Epidemiological Studies Depression Scale.

††Dependent for at least one activity of the Lawton IADL scale.

ł¥Defined as walking less than 1 hour/day and no sport activity.

$\S \S$ Systolic blood pressure $\geq 140 \mathrm{~mm} \mathrm{Hg}$ or diastolic blood pressure $\geq 90 \mathrm{~mm} \mathrm{Hg}$ or intake of antihypertensive drugs.

\थाTotal cholesterol concentration $\geq 6.20 \mathrm{mmol} / \mathrm{l}$ or intake of lipid lowering drugs.

cardiovascular deaths $(\mathrm{P}<0.001)$ and other causes of death $(\mathrm{P}=0.004)$, while there was no significant difference for cancer deaths $(\mathrm{P}=0.26)$. In each of these analyses, there was no significant difference in the cumulative incidence of death between the middle and highest thirds of walking speed, and the increased risk of death mainly concerned those in the lowest third of walking speed. Our subsequent results are for the lowest third of walking speed compared with the two upper thirds.

Table 2 shows multivariable analyses of the relation between walking speed and mortality. In analyses adjusted for age and sex (table 2, model 2), participants in the lowest third of walking speed had an increased risk of dying during follow-up (hazard ratio 1.64, 95\% confidence interval 1.24 to 2.17 ) compared with those in the upper thirds; the difference in mortality was significant for cardiovascular mortality $(2.85,1.64$ to 4.94$)$ and other causes of death $(1.79,1.00$ to 3.19$)$, while there was no association with deaths from cancer $(1.13,0.74$ to 1.71$)$. After adjustment for other covariates associated with walking speed, the association remained significant overall and for cardiovascular mortality (table 2, model 3). Further adjustment for baseline vascular risk factors, psychotropic drug use, exertional dyspnoea, peripheral artery disease, being dependent in at least one instrumental activity of daily living, depressive symptoms, and use of non-steroidal anti-inflammatory drugs for joint pain led to similar results (table 2, model 4). Inclusion of walking speed as a continuous variable or using other cut points (quartiles or quintiles) led to similar conclusions (data not shown).

Figure 2 shows the results of stratified analyses; in each strata, hazard ratios are adjusted for age, sex, BMI, height, education level, mini-mental state examination, physical activity, diabetes mellitus, hypertension, use of non-steroidal anti-inflammatory drugs for joint pain, psychotropic drug use, alcohol, smoking, dyslipidaemia, exertional dyspnoea, peripheral artery disease, dependence in instrumental activities of daily living, depressive symptoms, and homocysteine level (model 4). In all strata, cardiovascular mortality was higher in the lowest third of walking speed than in the upper thirds (model 4). Interaction tests comparing the hazard ratios across the strata were not significant.

In analyses in which we excluded those who were dependent in at least one instrumental activity of daily living at baseline $(171,5.3 \%$, table 1$)$, the hazard ratio (model 4 ) was 1.50 (1.08 to 2.08 ) for overall 
Table 2 | Relation between walking speed and risk of death, overall and from specific causes

\begin{tabular}{|c|c|c|c|c|c|c|c|}
\hline \multirow{2}{*}{$\begin{array}{l}\text { Cause of death and } \\
\text { walking speed }\end{array}$} & \multirow{2}{*}{$\begin{array}{l}\text { Person } \\
\text { years }\end{array}$} & \multirow[b]{2}{*}{ Events } & \multirow{2}{*}{$\begin{array}{l}\text { Rate } \\
(\% 0)\end{array}$} & \multicolumn{4}{|c|}{ Hazard ratio $(95 \% \mathrm{Cl})$, $\mathrm{P}$ value } \\
\hline & & & & Model 1* & Model $2 \dagger$ & Model $3 \ddagger$ & Model $4 \S$ \\
\hline \multicolumn{8}{|l|}{ All causes } \\
\hline 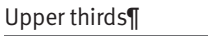 & 10940 & 104 & 9.5 & 1.00 & 1.00 & 1.00 & 1.00 \\
\hline Lower third** & 5474 & 105 & 19.2 & 2.07 (1.58 to 2.72$),<0.001$ & 1.64 (1.24 to 2.17$),<0.001$ & 1.58 (1.16 to 2.15), 0.002 & 1.44 (1.03 to 1.99$), 0.02$ \\
\hline \multicolumn{8}{|l|}{ Cancer } \\
\hline Upper thirds & 10940 & 59 & 5.4 & 1.00 & 1.00 & 1.00 & 1.00 \\
\hline Lower third** & 5474 & 40 & 7.3 & 1.38 (0.93 to 2.07 ), 0.11 & 1.13 (0.74 to 1.71$), 0.56$ & 1.04 (0.66 to 1.60$), 0.83$ & 1.03 (0.65 to 1.70$), 0.83$ \\
\hline \multicolumn{8}{|c|}{ Cardiovascular disease } \\
\hline Upper thirds $\mathbb{I}$ & 10940 & 21 & 1.9 & 1.00 & 1.00 & 1.00 & 1.00 \\
\hline Lower third** & 5474 & 38 & 6.9 & 3.66 (2.18 to 6.13$),<0.001$ & 2.85 (1.64 to 4.94), $<0.001$ & 3.00 (1.65 to 5.47$),<0.001$ & 2.92 (1.46 to 5.84), 0.002 \\
\hline \multicolumn{8}{|l|}{ Other causes } \\
\hline Upper thirds $\mathbb{R}$ & 10940 & 24 & 2.2 & 1.00 & 1.00 & 1.00 & 1.00 \\
\hline Lower third** & 5474 & 27 & 4.9 & 2.32 (1.38 to 3.88), 0.001 & 1.79 (1.00 to 3.19), 0.05 & 1.80 (0.96 to 3.35), 0.06 & 1.41 (0.74 to 2.67 ), 0.30 \\
\hline
\end{tabular}

*Unadjusted model.

†Adjusted for age and sex.

¥Adjusted for variables included in previous model plus body mass index (BMI), height, education level, mini-mental state examination, and physical activity.

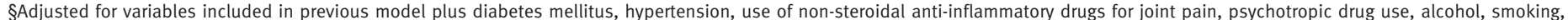

dyslipidaemia, exertional dyspnoea, peripheral artery disease, dependence for at least one instrumental activity of daily living, depressive symptoms, and homocysteine concentration.

TReference.

${ }^{\star *}$ Cut off for walking speed: $\leq 1.50 \mathrm{~m} / \mathrm{s}$ for men and $\leq 1.35 \mathrm{~m} / \mathrm{s}$ for women.

mortality and 3.13 (1.64 to 5.99) for cardiovascular mortality, while there was no association with other causes of death $(1.21,0.62$ to 2.38$)$ and cancer mortality $(1.10,0.68$ to 1.79$)$. In sensitivity analyses, we included participants who reported coronary artery disease at baseline and had a measurement of walking speed; our findings remained unchanged. Hazard ratios (model 4) were 1.41 (1.05 to 1.89 ) for overall mortality, 2.48 (1.33 to 4.62) for cardiovascular mortality, 1.11 (0.72 to 1.72$)$ for cancer mortality, and 1.34 (0.77 to 2.32) for other causes of death.

\section{DISCUSSION}

In this large cohort of older people living in the community we found that lower walking speed at baseline

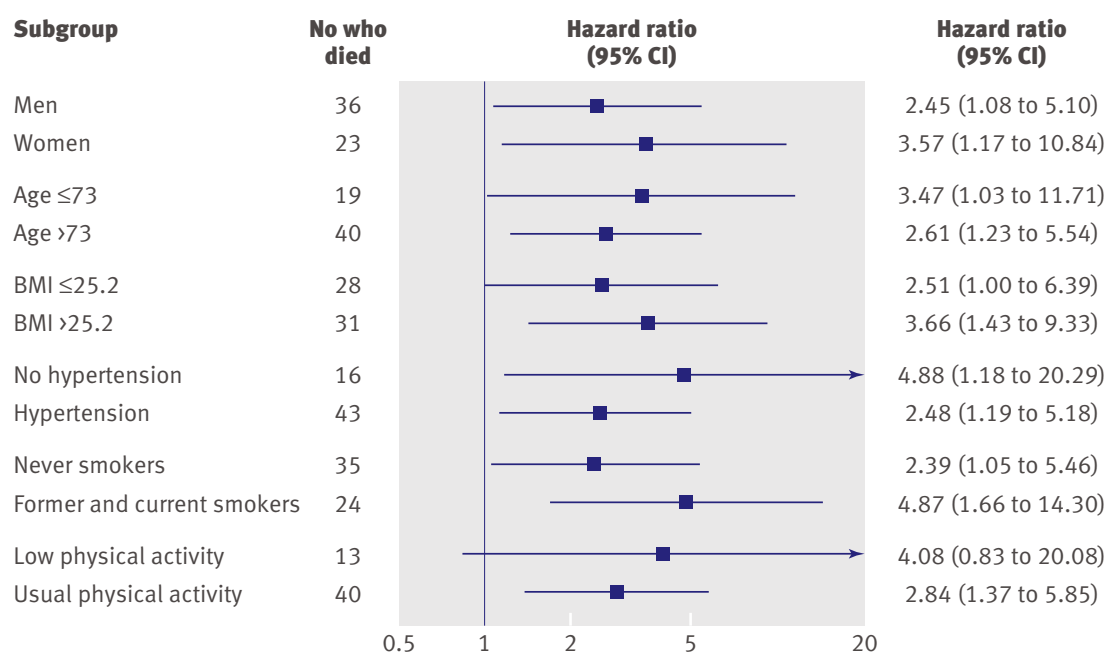

Fig 2 Walking speed in lowest third and risk of cardiovascular death: stratified analyses. Hazard ratios estimate relative risk of cardiovascular death in those in lowest third of walking speed ( $\leq 1.50 \mathrm{~m} / \mathrm{s}$ for men; $\leq 1.35 \mathrm{~m} / \mathrm{s}$ for women) compared with those in two highest thirds (reference group) was associated with increased mortality during a five year follow-up. Participants in the lowest third of walking speed had a $44 \%$ increased risk of death compared with those in the upper thirds. With regard to specific causes of death, participants in the lowest third of walking speed had about a threefold increased risk of cardiovascular death, while no relation was found with cancer mortality. This increased risk of cardiovascular death was seen in both sexes, younger as well as in older participants, those with or without a high risk vascular profile, and those with low or usual physical activity.

Findings in context and possible mechanisms

Few studies have investigated the relation between walking speed and mortality, and their methods were not uniform. ${ }^{13}$ One study found that regular walking speed below $1 \mathrm{~m} / \mathrm{s}$ was associated with mortality in older people, ${ }^{7}$ and another study found that a measure of walking speed alone provided information on mortality similar to that provided by a more complex evaluation of physical performance. ${ }^{8}$ It was unknown, however, whether specific causes of death accounted for this increased mortality. Our results show that the increased mortality observed in slow walkers was mostly cardiovascular mortality. Other causes of death tended to be higher in people with lower walking speed, but the relatively low number of events did not allow detailed analyses. Additionally, after adjustment for covariates associated with walking speed or death, the association between walking speed and other causes of death was considerably attenuated. Stratified analyses showed that the excess cardiovascular mortality among people who walked more slowly was observed in different subgroups. The relation between walking speed and mortality was not explained by inclusion of participants who were dependent in at least one instrumental activity of daily living at 


\section{WHAT IS ALREADY KNOWN ON THIS TOPIC}

Walking speed is a simple and reliable measure that is considered as a surrogate for overal quality of gait and motor function in older people

Decreased walking speed has been shown to be associated with several adverse health related events, including death

\section{WHAT THIS STUDY ADDS}

Participants with a walking speed in the lower third of the distribution had about a threefold increased risk of cardiovascular death, but no increased risk of mortality from cancer or other causes of death however, did not modify the association between lower walking speed and cardiovascular mortality. We should also consider that low physical activity, which was associated with decreased walking speed, might increase the prevalence of vascular risk factors such as hypertension ${ }^{29}$ or diabetes mellitus. ${ }^{30}$ However, the association remained after adjustment for, or stratification by, level of physical activity.

\section{Strengths and limitations}

The low proportion of participants who were lost to follow-up (eight out of 3208) is one of the main strengths of this study. Other strengths include the large number of person years and an automated measure of walking speed using photoelectric cells, which ensures high reproducibility of the measure.

There are limitations to consider. The $3 \mathrm{C}$ cohort was volunteer based and not representative of the general population. Participants were community dwelling, well functioning older people who were able to come by themselves to the study centre. Although this is likely to lead to an underestimation of the incidence of events such as death, it has been shown that, in this setting, the relation between baseline exposure and incidence of disease during follow-up is not biased. ${ }^{31}$ Increased cardiovascular mortality was present only for participants in the lowest third of walking speed, suggesting a threshold effect. The number of cardiovascular deaths, however, did not allow us to determine a more precise cut off.

\section{Conclusion}

In summary, lower walking speed was strongly associated with cardiovascular mortality in a population of well functioning older people. These findings show that assessment of motor performances in older people with simple measures such as walking speed can be performed easily and that the role of fitness in preserving life and function in older age is important.

Contributors: JD conducted the statistical analyses under the supervision of AE. All authors participated in designing the analyses, interpreting the results, and writing the manuscript. All authors had full access to the data and are guarantors for the study.

Funding: The $3 \mathrm{C}$ study is conducted under a partnership agreement between the Institut National de la Santé et de la Recherche Médicale (INSERM), the Victor Segalen-Bordeaux II University, and the SanofiSynthélabo Company. The Fondation pour la Recherche Médicale funded the preparation and initiation of the study. The 3C study is also supported by the Caisse Nationale Maladie des Travailleurs Salariés, Direction Générale de la Santé, Haute Autorité de la Santé, Institut National de Prévention et d'Education pour la Santé (INPES), Conseils Régionaux of Bourgogne, Fondation de France, Ministry of Research-INSERM Program, "Cohortes et collections de données biologiques," Mutuelle Générale de l'Education Nationale, Institut de la Longévité, Conseil Général de la Côte d'or. JD was supported by a PhD scholarship from the Fondation pour la Recherche Médicale. The funding organisations played no role in the design and conduct of the study, in the collection, management, analysis, and interpretation of the data, or in the preparation, review, or approval of the manuscript.

Competing interests: None declared.

Ethical approval: The study was approved by the ethical committee of the University Kremlin-Bicêtre Hospital; each participant signed an informed consent form.

Data sharing: No additional data available.
Alternative explanations are possible. Low walking speed might result from the peripheral effect of vascular risk factors-for example, heart failure or peripheral artery disease. ${ }^{28}$ Adjustment for these conditions, 
1 Hall WJ. Update in geriatrics. Ann Intern Med 2006;145:538-43.

2 Barak Y, Wagenaar RC, Holt KG. Gait characteristics of elderly people with a history of falls: a dynamic approach. Phys Ther 2006;86:1501-10.

3 Morita M, Takamura N, Kusano Y, Abe Y, Moji K, Takemoto T, et al. Relationship between falls and physical performance measures among community-dwelling elderly women in Japan. Aging Clin Exp Res 2005;17:211-6.

4 Guralnik JM, Ferrucci L, Pieper CF, Leveille SG, Markides KS, Ostir GV, et al. Lower extremity function and subsequent disability: consistency across studies, predictive models, and value of gait speed alone compared with the short physical performance battery. Gerontol A Biol Sci Med Sci 2000;55:M221-31.

5 Montero-Odasso M, Schapira M, Soriano ER, Varela M, Kaplan R, Camera LA, et al. Gait velocity as a single predictor of adverse events in healthy seniors aged 75 years and older. J Gerontol A Biol Sci Med Sci 2005;60:1304-9.

6 Penninx BW, Ferrucci L, Leveille SG, Rantanen T, Pahor M, Guralnik JM. Lower extremity performance in nondisabled older persons as a predictor of subsequent hospitalization. J Gerontol $A$ Biol Sci Med Sci 2000;55:M691-7.

7 Cesari M, Kritchevsky SB, Penninx BW, Nicklas BJ, Simonsick EM, Newman AB, et al. Prognostic value of usual gait speed in wellfunctioning older people-results from the health, aging and body composition study. J Am Geriatr Soc 2005;53:1675-80.

8 Ostir GV, Kuo YF, Berges IM, Markides KS, Ottenbacher KJ. Measures of lower body function and risk of mortality over 7 years of follow-up. Am J Epidemiol 2007;166:599-605.

9 Liston R, Mickelborough J, Bene J, Tallis R. A new classification of higher level gait disorders in patients with cerebral multi-infarct states. Age Ageing 2003;32:252-8.

10 Elbaz A, Ripert M, Tavernier B, Fevrier B, Zureik M, Gariepy J, et al. Common carotid artery intima-media thickness, carotid plaques, and walking speed. Stroke 2005;36:2198-202.

11 The 3C Study Group. Vascular factors and risk of dementia: design of the three-city study and baseline characteristics of the study population. Neuroepidemiology 2003;22:316-25.

12 Radloff LS. The CES-D scale: a self report depression scale for research in the general population. Appl Psychol Meas 1977;1:385-401.

13 Graham JE, Ostir GV, Kuo YF, Fisher SR, Ottenbacher KJ. Relationship between test methodology and mean velocity in timed walk tests: a review. Arch Phys Med Rehabil 2008;89:865-72.

14 Newman AB, Simonsick EM, Naydeck BL, Boudreau RM, Kritchevsky SB, Nevitt MC, et al. Association of long-distance corridor walk performance with mortality, cardiovascular disease, mobility limitation, and disability. JAMA 2006;295:2018-26.

15 Dobkin BH. Short-distance walking speed and timed walking distance: redundant measures for clinical trials? Neurology 2006;66:584-6.

16 Wei M, Kampert JB, Barlow CE, Nichaman MZ, Gibbons LW, Paffenbarger RS Jr, et al. Relationship between low cardiorespiratory fitness and mortality in normal-weight, overweight, and obese men JAMA 1999;282:1547-53.
17 Nocon M, Hiemann T, Muller-Riemenschneider F, Thalau F, Roll S Willich SN. Association of physical activity with all-cause and cardiovascular mortality: a systematic review and meta-analysis. Eur I Cardiovasc Prev Rehabil 2008;15:239-46.

18 Soumare A, Elbaz A, Ducros V, Tavernier B, Alperovitch A, Tzourio C. Cross-sectional association between homocysteine and motor function in the elderly. Neurology 2006;67:985-90

19 Volpato S, Ble A, Metter EJ, Lauretani F, Bandinelli S, Zuliani G, et al. High-density lipoprotein cholesterol and objective measures of lower extremity performance in older nondisabled persons: the InChianti study. J Am Geriatr Soc 2008; 56:621-9.

20 Cesari M, Penninx BW, Pahor M, Lauretani F, Corsi AM, Rhys Williams $\mathrm{G}$, et al. Inflammatory markers and physical performance in older persons: the InCHIANTI study. J Gerontol A Biol Sci Med Sci 2004;59:242-8.

21 Ridker PM, Hennekens CH, Buring JE, Rifai N. C-reactive protein and other markers of inflammation in the prediction of cardiovascular disease in women. N Engl J Med 2000;342:836-43.

22 Arvanitakis Z, Wilson RS, Bienias JL, Bennett DA. Diabetes and parkinsonian signs in older persons. Alzheimer Dis Assoc Disord 2007;21:144-9.

23 Soumare A, Elbaz A, Zhu Y, Maillard P, Crivello F, Tavernier B, et al. White matter lesions volume and motor performances in the elderly. Ann Neurol 2009;65:706-15.

24 Wolfson L, Wei X, Hall CB, Panzer V, Wakefield D, Benson RR, et al. Accrual of MRI white matter abnormalities in elderly with normal and impaired mobility. J Neurol Sci 2005;232:23-7.

25 Rosano C, Brach J, Longstreth Jr WT, Newman AB. Quantitative measures of gait characteristics indicate prevalence of underlying subclinical structural brain abnormalities in high-functioning older adults. Neuroepidemiology 2006;26:52-60.

26 Rosano C, Sigurdsson S, Siggeirsdottir K, Phillips CL, Garcia M, Jonsson PV, et al. Magnetization transfer imaging, white matter hyperintensities, brain atrophy and slower gait in older men and women. Neurobiol Aging 2008 Sep 5 [Epub ahead of print].

27 Baezner H, Blahak C, Poggesi A, Pantoni L, Inzitari D, Chabriat H, et al. Association of gait and balance disorders with age-related white matter changes: the LADIS study. Neurology 2008;70:935-42.

28 McDermott MM, Liu K, Ferrucci L, Criqui MH, Greenland P, Guralnik JM, et al. Physical performance in peripheral arteria disease: a slower rate of decline in patients who walk more. Ann Intern Med 2006;144:10-20.

29 Beunza JJ, Martinez-Gonzalez MA, Ebrahim S, Bes-Rastrollo M, Nunez J, Martinez JA, et al. Sedentary behaviors and the risk of incident hypertension: the SUN Cohort. Am J Hypertens 2007;20:1156-62.

$30 \mathrm{Hu}$ FB, Li TY, Colditz GA, Willett WC, Manson JE. Television watching and other sedentary behaviors in relation to risk of obesity and type 2 diabetes mellitus in women. JAMA 2003;289:1785-91.

31 Criqui MH. Response bias and risk ratios in epidemiologic studies. Am J Epidemiol 1979;109:394-9.

Accepted: 28 August 2009 